\section{$\underset{\substack{\text { hommes } \\ \text { \& migrations }}}{ }$}

\section{Hommes \& migrations}

Revue française de référence sur les dynamiques

migratoires

1312 | 2015

Diasporas iraniennes

\title{
Pour conclure
}

\section{Fariba Adelkhah}

\section{(2) OpenEdition \\ Journals}

\section{Édition électronique}

URL : http://journals.openedition.org/hommesmigrations/3501

DOI : 10.4000/hommesmigrations.3501

ISSN : 2262-3353

\section{Éditeur}

Musée national de l'histoire de l'immigration

\section{Édition imprimée}

Date de publication : 1 octobre 2015

Pagination : 98-99

ISBN : 978-2-919040-33-9

ISSN : $1142-852 X$

\section{Référence électronique}

Fariba Adelkhah, «Pour conclure », Hommes \& migrations [En ligne], 1312 | 2015, mis en ligne le 01 octobre 2018, consulté le 03 mai 2019. URL : http://journals.openedition.org/ hommesmigrations/3501; DOI : 10.4000/hommesmigrations.3501 


\section{POUR CONCLURE}

par FARIBA ADELKHAH, politologue, Sciences Po-CERI.

Le grand mérite de ce numéro d'Hommes \& Migrations est de prendre au sérieux le fait migratoire ou diasporique et la pratique sociale du voyage. Ces phénomènes ne relèvent pas d'un effet de mode scientifique quaurait engendré la globalisation, même si la conscience accrue de cette dernière, depuis une trentaine d'années, a contribué à la prolifération d'études et l'a précisément érigée en genre universitaire, voire en quasi-discipline. Les articles rassemblés dans ce dossier en relèvent. Ils éclairent des dimensions mal connues, par exemple l'émigration iranienne en Arménie ou la littérature iranienne de langue anglaise.

L'essentiel est de bien voir que cette mobilité des Iraniens est antérieure à la phase actuelle de la globalisation, tout en y participant. De tout temps, les Iraniens se sont déplacés et expatriés - pour prendre un terme contemporain un peu anachronique, et très problématique, puisque le Français résidant en Iran est un expatrié, alors que l'Iranien vivant en France est un immigré (ou un réfugié)! Autrement dit, les Iraniens, tel Monsieur Jourdain pour la prose, faisaient de la globalisation sans le savoir. Au point que la culture "iranienne" a largement été créée au-delà des frontières du pays : en Asie centrale, en Asie du Sud et du Sud-Est, dans l'Empire ottoman ou russe, en Afghanistan, sur les terres arabes ou, plus récemment, en Europe et en Amérique. Pour nous en tenir à la période contemporaine de la formation de l'État-nation, il suffit d'avoir à l'esprit le rôle d'Oxford, de Paris, de Genève, de Bruxelles et de Berlin, ou encore de Tiflis - l'actuelle Tbilissi, où siégeait, au XIX siècle, le vice-roi du Caucase, annexée par l'Empire des Romanov, et qui devint un centre culturel cosmopolite de première importance -, d'Istanbul et de Bombay dans lémergence de la pensée et de la langue iraniennes modernes, à l'initiative de nombreux lettrés qajar qui s'y établirent, y publièrent les premiers textes en persan de facture occidentale, y réformèrent la langue et y créèrent la figure de l'intellectuel iranien moderne. De ce point de vue, le cas du groupe des "Berlinois" et de leurs revues Kaveh (1916-1922) et Iranshahr (1922-1927) a été emblématique par son influence sur la littérature et l'idéologie nationales, puis sur le parti communiste Toudeh, dans la première moitié du XXe siècle ${ }^{1}$. Mais les clercs nont pas été en reste. Au moins depuis le XVIII siècle, ils exercent leur magistère à partir des villes saintes de Mésopotamie ou à partir du Liban : tel fut le cas de l'imam Khomeyni lui-même, exilé à Nadjaf de 1965 à 1978, ou encore de Moussa Sadr, grand réformateur du chiisme libanais dès le début des années 1960. En bref, le voyage est un fait social total, qui est comme le microcosme de l'Iran, comme sa miniature.

Aussi les Iraniens quittent-ils l'Iran pour mieux y rentrer, ou pour mieux le refonder. Certes, le voyage est un laboratoire où s'expérimentent le changement et l'innovation. Mais ces transformations, paradoxalement, sont souvent d'orientation conservatrice. Elles reproduisent un Iran de pacotille et suranné, avec ses colonnes de Persépolis en plâtre et 
sa musique de cabaret des années 1970, un modèle familial fermé sur lui-même et peu propice à l'émancipation des femmes, la centralité de la religion dans la sociabilité et la respectabilité, le cloisonnement ethnique et confessionnel, comme j'ai pu le constater dans mes propres recherches ${ }^{2}$. En tout cas, les Iraniens de ou à l'étranger ont souvent tendance à surjouer leur iranité, à grand renfort de traditions inventées, au sens où l'entendaient Eric Hobsbawm et Terence Ranger ${ }^{3}$. Les Iraniens de Los Angeles sont passés maîtres à ce petit jeu ${ }^{4}$. De ce fait, l'émigration est peut-être moins une expérience d'individuation, comme le suggèrent plusieurs articles de cet ensemble, qu'un processus d'autonomisation du social par rapport au contrôle de l'État, dont l'individuation est une dimension. Bien que son expatriation soit souvent une épopée, ou en tout cas soit volontiers vécue comme telle par l'intéressé et par sa famille, l'Iranien qui voyage reste profondément inséré, à travers l'exil, dans des rapports sociaux d'ordre familial, religieux, économique, ethnique, voire politique. Des rapports sociaux qui reproduisent la société iranienne tout en lui permettant une plus grande marge de manœuvre par rapport à la puissance publique.

Il ne s'agit nullement de postuler une dissociation entre l'État et la diaspora, et ce d'autant moins que la République islamique s'est efforcée de se réconcilier avec celle-ci, depuis les années 1990, comme le rappellent les articles du numéro, et que plusieurs de ses institutions sont partie prenante de l'économie informelle transfrontalière et du contournement des sanctions internationales. Néanmoins, les Iraniens de l'étranger ont gagné en agency, pour reprendre un terme scientifique à la mode, et en font profiter leur famille ou leur lieu d'origine, en particulier par le biais des remises (remittances) de diverses natures, sociales autant que financières, et de lévergétisme transnational. La naïveté consisterait à croire que cette autonomisation du social à la faveur de l'expatriation est en soi porteuse d'ouverture, de progressisme, de "modernité", au nom d'une conception très normative, élitiste et assez niaise de la "société civile", à laquelle adhèrent volontiers les "réformateurs" proches de Mohamad Khatami, président de la République de 1997 à 2005. La cruelle vérité est que la diaspora charrie souvent des représentations culturelles, des pratiques sociales, une pensée politique très conservatrices, sinon réactionnaires. La famille, unité de base irréductible de la société iranienne, fût-elle expatriée, ou le marché matrimonial, avec ses mariages transnationaux arrangés, souvent au sein de la parenté élargie, et célébrés off shore dans les hôtels luxueux d'Istanbul et de Dubaï, en sont de bons sites d'observation. Ce qui prouve au moins que les Iraniens sont des émigrés comme les autres, car ils n'ont pas, de par le monde, le monopole de ce conservatisme diasporique. À l'étranger, on cherche toujours à entretenir et à retrouver ses racines, quitte à les inventer.

Le changement dont est porteur la pratique du voyage passe ironiquement par cet attachement grégaire à une culture et à un pays que l'on a quittés depuis plus ou moins longtemps, et qui continuent à se transformer sans que l'on en soit conscient. La chanteuse irangelesi (de Los Angeles) Leila Forouhar, avec l'un de ses derniers titres, Sarzaminam ( $M a$ Terre), est très révélatrice de ce nationalisme étriqué et doloriste, tourné vers le passé ${ }^{5}$. Pourtant, plusieurs des articles de cet ensemble le montrent, changement il y a bien. Mais celui-ci se déguise sous les atours de la continuité, de la répétition, de l'exaltation du passé et des origines. Et il procède d'une temporalité plus longue dont on ne mesure pas immédiatement les effets. Il résulte aussi d'une mise en relation triangulaire et complexe des milieux expatriés, de leur société d'accueil et de leur société de départ. Une mise en synergie dont l'alchimie, économique, culturelle ou conjugale, ne porte ses fruits que dans la durée, et de manière contradictoire. Autant dire que la relation entre l'expatriation et les transformations sociales n'est pas univoque et revêt simultanément le masque de la rupture et de la continuité. 